\title{
Atherosclerosis is inversely associated with renal function
}

Autopsy data show that atherosclerotic lesions are more likely to be present in individuals who had chronic kidney disease (CKD) before death than in individuals who did not. Nakano et al. now demonstrate an inverse association between the presence of severe atherosclerotic lesions in main coronary arteries and pre mortem kidney function in individuals with CKD.

The Hisayama Study has continuously recorded extensive health-related data on the residents of the Japanese town of Hisayama since 1961. Between 1988 and 2005 , autopsies were performed in 844 of 1,162 Hisayama residents who died over this period. Nakano et al. classified 482 individuals for whom health examination

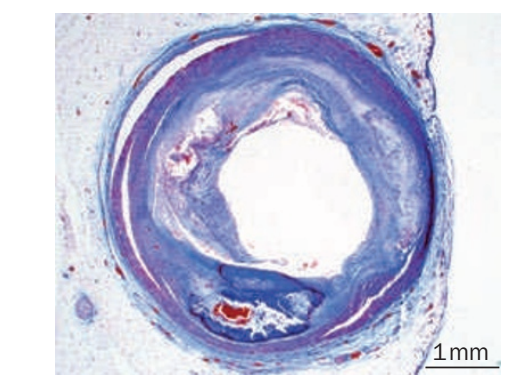

Severe artery lesion associated with low eGFR. Courtesy of Dr Toshiaki Nakano, Kyushu University, Fukuoka, Japan. data were available for the 3 years before death into four categories on the basis of their estimated glomerular filtration rate (eGFR). The researchers then analyzed the autopsy results from a random sample of 126 individuals from the four eGFR categories.

Atherosclerotic lesions identified in samples of main coronary arteries were classified into six types of increasing severity as per the definitions proposed by the American Heart Association Committee on Vascular Lesions of the Council on Atherosclerosis. Nakano et al. found that a significantly higher proportion of individuals with eGFRs $30-44 \mathrm{ml} / \mathrm{min} / 1.73 \mathrm{~m}^{2}$ and $<30 \mathrm{ml} /$ $\mathrm{min} / 1.73 \mathrm{~m}^{2}$ had advanced atherosclerotic lesions (types IV-VI) than individuals with an $\mathrm{eGFR} \geq 60 \mathrm{ml} / \mathrm{min} / 1.73 \mathrm{~m}^{2}(52.3 \%$ and $52.8 \%$ versus $33.6 \%$, respectively). Moreover, after adjusting for potential confounding factors, individuals with an eGFR $<45 \mathrm{ml} / \mathrm{min} / 1.73 \mathrm{~m}^{2}$ had a twofold risk of advanced atherosclerosis (lesions types IV-VI) compared with individuals with an eGFR $\geq 60 \mathrm{ml} / \mathrm{min} / 1.73 \mathrm{~m}^{2}$. Prevalence of coronary artery calcified lesions was $36.5 \%, 37.0 \%, 44.9 \%$ and $60.4 \%$ in individuals with eGFRs $\geq 60 \mathrm{ml} / \mathrm{min} / 1.73 \mathrm{~m}^{2}, 45-59 \mathrm{ml} /$ $\mathrm{min} / 1.73 \mathrm{~m}^{2}, 30-44 \mathrm{ml} / \mathrm{min} / 1.73 \mathrm{~m}^{2}$ and $<30 \mathrm{ml} / \mathrm{min} / 1.73 \mathrm{~m}^{2}$, respectively $(P$ value for trend $=0.02)$. The multivariate-adjusted odds ratio for calcified lesions was 4.71 in individuals with an $\mathrm{eGFR}<30 \mathrm{ml} / \mathrm{min} / 1.73 \mathrm{~m}^{2}$ compared with individuals with an eGFR $\geq 60 \mathrm{ml} / \mathrm{min} / 1.73 \mathrm{~m}^{2}$.

According to Nakano et al., their study suffers from a few limitations, such as a high prevalence of data from elderly individuals, a cross-sectional design and a lack of data on minor risk factors for cardiovascular disease. Nevertheless, the researchers conclude that their evidence showing that severity of atherosclerosis gradually increases with decreasing renal function in individuals with $\mathrm{CKD}$ highlights the importance of monitoring kidney function in patients with moderate CKD to implement strategies that could reduce the prevalence and severity of coronary atherosclerosis.

Baldo Lucchese

Original article Nakano, T. et al. Association of kidney
function with coronary atherosclerosis and calcification
in autopsy samples from Japanese elders: the Hisayama
study. Am. J. Kidney Dis. 55, 21-30 (2010)

